\title{
Feminicidio: asfixia mecánica por estrangulamiento. Morgue de Lima 2009-2010
}

\author{
Shérmany Aronés, Rosa Carrera, Denisse Astuhuamán, Kelly Casana, Jessica Santillán, \\ Karina Pariona \\ Instituto de Medicina Legal, Ministerio Público, e Instituto de Patología, UNMSM
}

Introducción: Feminicidio, delito incorporado al Art.107 del Código penal, por ley 29819, es cuando la víctima es mujer, en relaciones familiares o de pareja; analizamos la muerte por agente mecánico constrictor al cuello estrangulador.

Objetivos: Establecer la incidencia de feminicidio por asfixia mecánica, modalidad estrangulamiento.

Diseño: Cuantitativo, observacional, transversal.

Institución: Instituto Medicina Legal, Ministerio Público, e Instituto de Patología, UNMSM.

Material de estudio: Informes periciales de necropsias ingresadas a Morgue Central de Lima, de cadáveres con diagnóstico de asfixia mecánica por constricción, modalidad estrangulamiento.

Intervenciones: Médico legales, por denuncia al Ministerio Público por muerte violenta.

Principales medidas de resultados: Medidas de tendencia central porcentual.

Resultados: Se seleccionó 3,26\% (288) muertes con asfixia mecánica por constricción cervical, del total de 8833 muertes necropsiadas (2009 a 2010); 81\% (233) fueron ahorcaduras y 19\% (55) estrangulamientos; sexo masculino $54,6 \%$ (30), femenino 45,5\% (25); de 20 a 50 años 60\% (15), de 10 a 17 años 24\% (6), >50 años 16\% (4), con pareja 44\% (11), con esposo $12 \%(3)$, sin pareja conocida $56 \%(14)$, en domicilio $48 \%(12)$, hotel-habitación $28 \%$ (7), vía pública $24 \%(6)$, con alcoholemia 16\% (4), con otros violencia $96 \%(24)$, sin signos $4 \%(1)$.

Conclusiones: La modalidad asfixia por constricción estrangulamiento en feminicidio correspondió a 45,5\%, con violencia añadida 96\%, con pareja conocida 44\%, ocurrencia domiciliaria $48 \%$ e ingesta de alcohol $16 \%$; solo $8 \%$ con signos de gestación.

Palabras clave: Feminicidio; estrangulamiento.

\section{Calidad nutricional de un producto extruido fortificado con dos niveles de hierro, proveniente de harina de sangre bovina}

\author{
Ronny Galarza, Yadira Cairo \\ EAP de Nutrición, Facultad de Medicina, UNMSM
}

Objetivos: Determinar la calidad nutricional de un producto extruido fortificado con dos niveles de hierro proveniente de harina de sangre bovina.

Diseño: Tecnológico experimental.

Institución: EAP de Nutrición, Facultad de Medicina, UNMSM.

Participantes: Escolares, para las pruebas sensoriales.

Intervenciones: En la planta piloto de la Facultad de Industrias Alimentarias, UNALM, se obtuvo la harina de sangre bovina, a partir de un secado por atomización. Con ello se formuló dos niveles de fortificación de $10 \%$ y $15 \%$, además de un producto sin fortificar (0i\%). Para la obtención del producto extruido se utilizó un extrusor de un tornillo sinfín. La calidad nutricional se determinó a partir del contenido de hierro, análisis proximal, físicoquímico, microbiológico y la prueba de aceptabilidad en 60 escolares, para las pruebas sensoriales.

Principales medidas de resultados: Contenido de hierro y prueba de aceptabilidad en 60 escolares del producto extruido fortificado.

Resultados: Los productos extruidos fortificados con $10 \%$ y $15 \%$ presentaron un elevado contenido de hierro, 31,9 $\mathrm{mg} / 100 \mathrm{~g}$ y $38,1 \mathrm{mg} / 100 \mathrm{~g}$, respectivamente, en comparación con el producto extruido sin fortificar (0i\%), que fue de $2,9 \mathrm{mg} / 100 \mathrm{ig}$.

Conclusiones: El producto extruido fortificado con $10 \%$ de hierro proveniente de harina de sangre bovina presentó una adecuada calidad nutricional y fue más aceptable que el producto extruido fortificado con $15 \%$.

Palabras clave: Harina de sangre bovina, producto extruido fortificado, calidad nutricional, hierro. 